Folia Cardiologica 2017 tom 12 , nr 2, strony $216-219$ DOI: $10.5603 / F C .2017 .0035$ Copyright (C) 2017 Via Medica ISSN 2353-7752

\title{
Śluzak lewej komory serca powikłany zatorowością obwodową
}

\author{
Left ventricular myxoma complicated by peripheral embolism
}

\author{
Dariusz Dąbrowski ${ }^{1}$, Anna Goździk², Aleksandra Milnerowicz ${ }^{3}$, Jacek Jakubaszko ${ }^{2}$, \\ Waldemar Goździk ${ }^{4}$, Wojciech Kosmala ${ }^{5}$ \\ ${ }^{1}$ NZOZ Cardiamed s.j. w Legnicy \\ ${ }^{2}$ Katedra i Klinika Chirurgii Serca Uniwersytetu Medycznego we Wrocławiu \\ ${ }^{3}$ Katedra i Klinika Chirurgii Naczyniowej Uniwersytetu Medycznego we Wrocławiu \\ ${ }^{4}$ Katedra i Klinika Anestezjologii i Intensywnej Terapii Uniwersytetu Medycznego we Wrocławiu \\ ${ }^{5}$ Katedra i Klinika Kardiologii Uniwersytetu Medycznego we Wrocławiu
}

\section{Streszczenie}

Śluzak lewej komory jest bardzo rzadkim, łagodnym guzem pierwotnym serca. Ze względu na umiejscowienie, wielkość oraz ruchomość może być źródłem zatorowości obwodowej. Nawrót śluzaka po chirurgicznym usunięciu jest rzadki i wynosi $0-3 \%$ w przypadkach guzów odosobnionych i $12-22 \%$ w postaciach występujących rodzinnie.

Przedstawiono dwa przypadki śluzaków lewej komory serca powikłanych zatorowością tętnic kończyn dolnych. W pierwszym przypadku u 19-letniego mężczyzny, oprócz zatorowości obwodowej, stwierdzono szybki rozrost guza, który mógł sugerować tworzenie się skrzepliny. W 2. przypadku u 42-letniego mężczyzny 2 miesiące po operacyjnym usunięciu śluzaka zaobserwowano odrośnięcie guza w koniuszku lewej komory oraz pojawienie się dodatkowo dwóch guzów w jamie prawego przedsionka. Cechy kliniczne śluzaka serca zarówno w kontekście powikłań, jak i jego nawrotów nakazują wnikliwą obserwacje, w tym kontrolę echokardiograficzną, u wszystkich chorych po chirurgicznym usunięciu tego nowotworu.

Słowa kluczowe: śluzak, lewa komora serca, zatorowość

Folia Cardiologica 2017; 12, 2: 216-219

\section{Wstęp}

Śluzak serca, należący do grupy rzadkich, występujących z częstością między 0,0017\% a 0,19\% pierwotnych nowotworów serca, jest łagodnym guzem rozwijającym się z wsierdzia ściennego [1, 2]. Śluzaki mogą się umiejscowić w każdej z 4 jam serca, najczęściej jednak, bo w 86\%, lokalizują się w przedsionkach, głównie w lewym, gdzie wyrastają z przegrody międzyprzedsionkowej na obrzeżu dołu owalnego [3]. W 90\% występują u kobiet w wieku między 30. a 60. rokiem życia. W $10 \%$ mogą się pojawiać rodzinnie, między innymi jako składowa zespołu Carneya, w którym towarzyszą im guzy jąder, przysadki, zespół Cushinga lub znamiona błękitne na skórze [4].

Objawy śluzaka serca są ściśle powiązane z jego lokalizacją, wielkością i ruchomością. Należą do nich zaburzenia rytmu serca, zmęczenie, bóle stawowe, gorączka, zmniejszenie masy ciała, niewydolność serca oraz nagły zgon. W części przypadków przebieg jest asymptomatyczny. Główne powikłanie, występujące u 30-50\% pacjentów, stanowi zatorowość ściśle powiązana ze śmiertelnością, zwłaszcza przedoperacyjną. Dotyczy ona głównie naczyń mózgowych, rzadziej wieńcowych, nerkowych oraz kończyn dolnych i górnych [5]. 


\section{Opis przypadków}

\section{Przypadek 1.}

Mężczyzna w wieku 19 lat został przyjęty do Kliniki Chirurgii Naczyniowej Uniwersyteckiego Szpitala Klinicznego we Wrocławiu z powodu obustronnej niedrożności tętnic udowych, gdzie w trybie pilnym wykonano zabieg operacyjny embolektomii. W badaniach laboratoryjnych wykazano podwyższone stężenie fibrynogenu do 6,4 (1, [1,8-3,5], 5) i D-dimerów do 5,03 (0-0,5). W badaniu echokardiograficznym w lewej komorze stwierdzono niewielki, mocniej wysycony owalny guzek pomiędzy mięśniami brodawkowatymi bocznym i przyśrodkowym o wymiarach $5 \mathrm{~mm} \times 4 \mathrm{~mm}$. Poza tym obraz serca był prawidłowy. Po kilku dniach w okresie pooperacyjnym, wykonano kontrolną echokardiografię, w której wykazano progresję wielkości guza do $12 \mathrm{~mm} \times$ $13 \mathrm{~mm}$ (ryc. 1). Obraz sugerował rozpoznanie skrzepliny wewnątrzsercowej, w związku z czym zintensyfikowano prowadzone od początku hospitalizacji leczenie przeciwzakrzepowe. Mimo 3-tygodniowego dożylnego wlewu heparyny

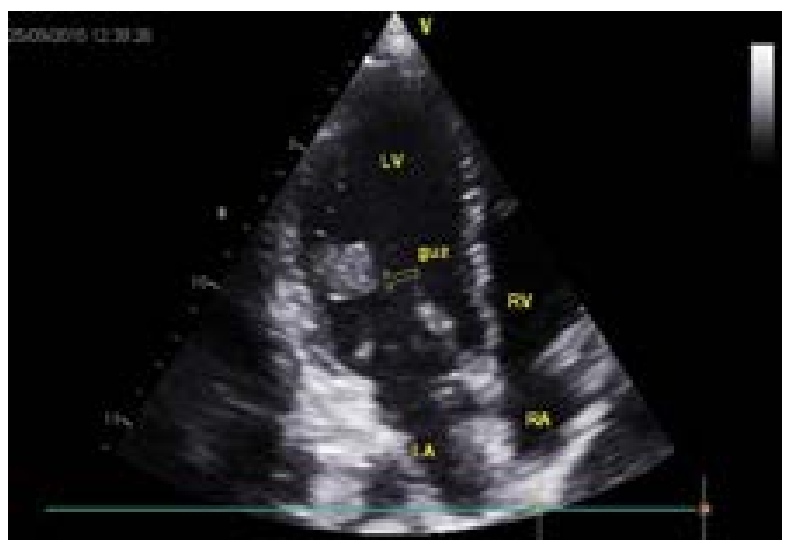

Rycina 1. Echokardiografia przezklatkowa, projekcja koniuszkowa 4-jamowa: guz lewej komory o wymiarach $14 \mathrm{~mm} \times 17 \mathrm{~mm}$; LV (left ventricle) - lewa komora; LA (left atrium) - lewy przedsionek; RV (right ventricle) - prawa komora; RA (right atrium) - prawy przedsionek

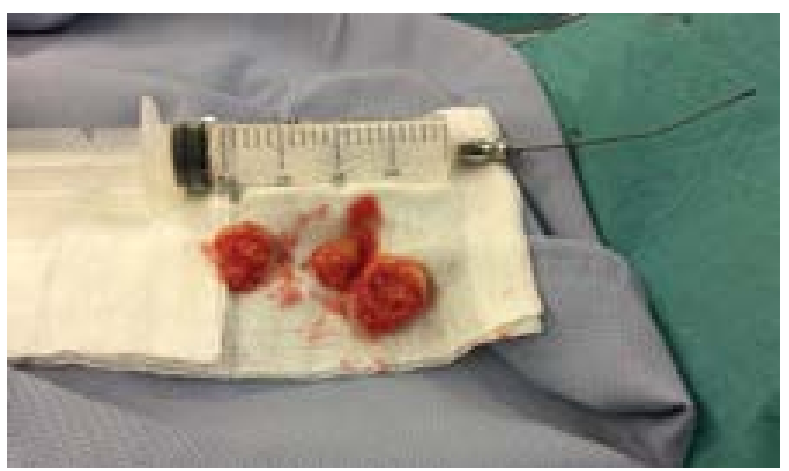

Rycina 2. Obraz śródoperacyjny: kawałki usuniętego guza w pełnych dawkach, z APTT 150-200 ms, guz wykazywał dalszą tendencję wzrostową, co było powodem podjęcia decyzji o operacji kardiochirurgicznej.

W krążeniu pozaustrojowym po nacięciu prawego przedsionka i przejściu przez otwór owalny i zastawkę mitralną uzyskano dostęp do guza, który usunięto w maksymalnym możliwym zakresie (ryc. 2). Pacjenta wypisano do domu w dobrym stanie ogólnym w 16 . dobie po operacji. W badaniu histopatologicznym usuniętego guza rozpoznano śluzaka serca.

\section{Przypadek 2.}

Dwa tygodnie później do Kliniki Chirurgii Serca Uniwersyteckiego Szpitala Klinicznego we Wrocławiu przyjęto 42-letniego mężczyznę w celu pilnej operacji w związku z podejrzeniem zakrzepu wychodzącego z koniuszka serca. W koronarografii uwidoczniono amputacje gałęzi przedniej zstępującej (LAD, left anterior descending) przy nieobecności istotnych przewężeń w pozostałych tętnicach wieńcowych.

Z powodu dużego rozmiaru guza $(20 \times 30 \mathrm{~mm}$, ryc. 3) balotującego $w$ świetle lewej komory serca w trybie pilnym wykonano zabieg usunięcia zmiany poprzez nacięcie ściany przedniej lewej komory. Guz był niejednolity, przytwierdzony do beleczkowania lewej komory, bez szypuły i usuwano go techniką „po kawałku” bez zastosowania elektrokoagulacji. Zabieg wykonano po uprzednim założeniu przęsła tętniczego z lewej tętnicy piersiowej wewnętrznej (LIMA, left internal mammary artery) do LAD. Operację monitorowano za pomocą echokardiografii przezprzełykowej. Przebieg pooperacyjny był niepowikłany. Pacjenta wypisano do domu w 10. dobie po zabiegu. Badanie histopatologiczne guza ujawniło śluzaka serca.

Po 2 miesiącach mężczyzna został ponownie przyjęty do Kliniki Chirurgii Serca w związku ze stwierdzeniem

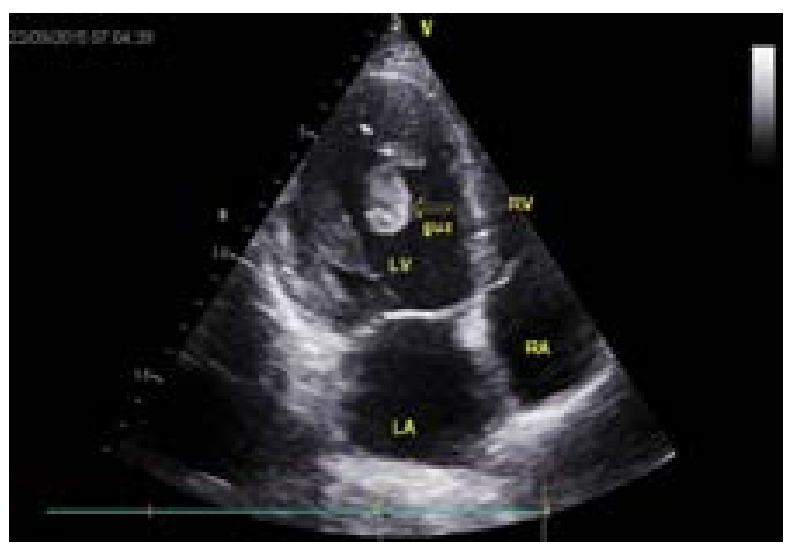

Rycina 3. Echokardiografia przezklatkowa, projekcja koniuszkowa 4-jamowa: guz wychodzący z koniuszka serca; LV (left ventricle) - lewa komora; LA (left atrium) - lewy przedsionek; RV (right ventricle) - prawa komora; RA (right atrium) - prawy przedsionek 


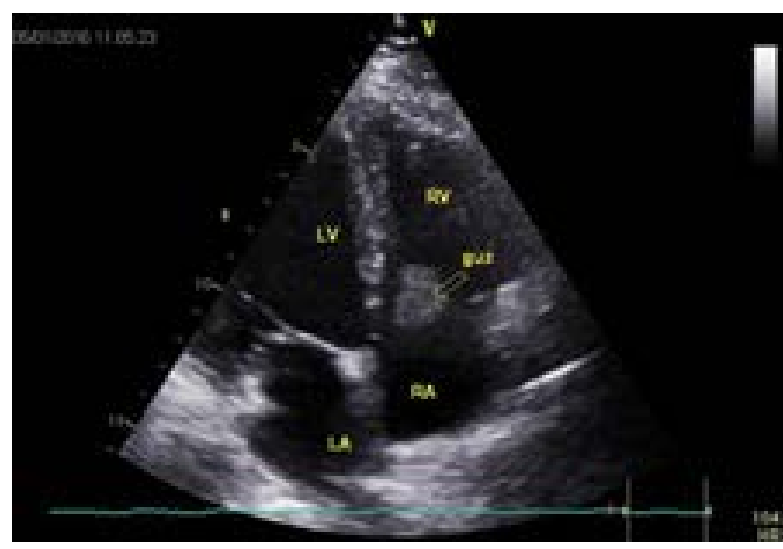

Rycina 4. Echokardiografia przezklatkowa, projekcja koniuszkowa 4-jamowa: guz prawego przedsionka; LV (left ventricle) - lewa komora; LA (left atrium) - lewy przedsionek; RV (right ventricle) prawa komora; RA (right atrium) - prawy przedsionek

w badaniu echokardiograficznym guza w jamie lewej komory o podobnej, jak poprzednio, lokalizacji oraz drugiego guza w prawym przedsionku, poprzednio nieobserwowanego (ryc. 4). Z wywiadu od pacjenta uzyskano informację, że tydzień wcześniej przebył zabieg operacyjny trombektomii $\mathrm{w}$ miejscu podziału aorty i tętnic biodrowych oraz trombendanderektomii prawej tętnicy udowej powierzchownej.

Z wykorzystaniem krążenia pozaustrojowego wykonano ponowny zabieg usunięcia guza z lewej komory serca oraz stwierdzonych śródoperacyjnie dwóch guzów z prawego przedsionka. W badaniu histopatologicznym rozpoznano śluzaka lewej komory i prawego przedsionka.

\section{Dyskusja}

Lewa komora serca jest rzadką lokalizacją śluzaka, dotyczącą około 5\% wszystkich przypadków [6]. Guz zwykle wyrasta z przegrody międzykomorowej, w pobliżu drogi odpływu, bądź z zastawki mitralnej, z wolnej ściany lewej komory lub bardzo rzadko z zastawki aortalnej $[7,8]$. Podstawowym badaniem diagnostycznym w identyfikacji śluzaka serca jest echokardiografia. W celu dokładniejszej weryfikacji rozpoznania można się posłużyć tomografią komputerową lub rezonansem magnetycznym.

Obecność śluzaka, zwłaszcza w lewej komorze, sprzyja zatorowości obwodowej [9] i dlatego szybkie chirurgiczne usunięcie guza jest najefektywniejszą metodą leczenia i jednocześnie skuteczną profilaktyką przeciwzatorową.
Bardzo ważnym elementem determinującym powikłania zatorowe jest morfologia guza. Makroskopowo wyróżnia się dwa typy śluzaków: pierwszy - nieregularny, o nierównej, kosmkowej powierzchni i miękkiej konsystencji, będący częściej przyczyną embolizacji oraz drugi - polipoidalny, o zwartej konsystencji i gładkiej powierzchni. Niezależnie od postaci strukturalnej większe śluzaki, o większej powierzchni, częściej ulegają fragmentaryzacji, stając się źródłem zatorów. Dane literaturowe sugerują również, że rozwojowi zatorowości w przebiegu śluzaka sprzyja zwiększona objętość i ilość płytek krwi [10]. Zaburzenia funkcji trombocytów, w szczególności jakościowe, mogą się wiązać z aktywacją cytokin prozapalnych towarzyszącą śluzakom serca [11].

Nawrót śluzaka po chirurgicznym usunięciu stwierdza się rzadko; jego częstość ocenia się na 0-3\% w przypadku guzów odosobnionych i na 12-22\% w postaciach występujących rodzinnie, w większości uwarunkowanych mutacją genu PRKAR1A (chromosom 17q 22-24). Objawy nawrotu są najczęściej diagnozowane w okresie pierwszych 4 lat po operacji. Z badań echokardiograficznych wynika, że przeciętny wzrost śluzaka może wynosić około 0,15 mm w ciągu miesiąca i $18 \mathrm{~mm}$ w ciągu roku [12].

\section{Podsumowanie}

Autorzy przedstawili dwa przypadki rzadkiej lokalizacji śluzaków serca w obrębie lewej komory powikłanych zatorowością obwodową. U pierwszego pacjenta obserwowano bardzo szybki rozrost guza. U drugiego chorego oprócz zatorowości doszło także do nawrotu śluzaka w okresie 2 miesięcy po pierwszej operacji. Reasumując należy podkreślić, że:

- resekcja guza z lewej komory serca jest zabiegiem trudnym technicznie, wymagającym dokładnego wypreparowania guza z beleczkowania jamy lewej komory;

- leczenie operacyjne w przypadku śluzaka to postępowanie z wyboru i ze względu na ryzyko zatorowe powinno być podjęte niezwłocznie;

- cechy kliniczne śluzaka serca, zarówno w kontekście powikłań, jak i jego nawrotów, nakazują wnikliwą obserwację, w tym kontrolę echokardiograficzną, u wszystkich chorych po chirurgicznym usunięciu tego nowotworu.

\section{Konflikt interesów}

Autorzy nie zgłaszają konfliktu interesów. 


\section{Abstract}

Left ventricular myxoma is a very rare, benign primary cardiac tumor. Due to its localization, size and mobility, it may be a source of peripheral embolism. The recurrence of myxoma after surgical removal is rare, ranging from $0 \%$ to $3 \%$ in solitary tumors and $12-22 \%$ in the familial type.

We report two cases of left ventricular myxomas complicated by arterial embolism. In the first case of a 19-years old male, apart from systemic embolisation, a very fast tumor growth, suggesting thrombus formation, was observed. In the second case of a 42-years old male, the recurrence of myxoma in left ventricle apex was found 2 months after surgical excision, together with de novo development of two additional tumors in the right atrium. Clinical features of cardiac myxoma, both in terms of complications and recurrences, necessitate careful follow up with an echocardiographic control in all patients after tumor removal surgery.

Key words: left ventricular, myxoma, embolism

Folia Cardiologica 2017; 12, 2: 216-219

\section{Piśmiennictwo}

1. Butany J, Nair V, Naseemuddin A, et al. Cardiac tumours: diagnosis and management. Lancet Oncol. 2005; 6(4): 219-228, doi: 10.1016/ S1470-2045(05)70093-0, indexed in Pubmed: 15811617.

2. Bjessmo S, Ivert T. Cardiac myxoma: 40 years' experience in 63 patients. Ann Thorac Surg. 1997; 63(3): 697-700, indexed in Pubmed: 9066386.

3. Yuan SM. Glandular cardiac myxoma: case report with literature review. Folia Morphol (Warsz). 2014; 73(3): 374-382, doi: 10.5603/ FM.2014.0056, indexed in Pubmed: 25242353.

4. Waller DA, Ettles DF, Saunders NR, et al. Recurrent cardiac myxoma: the surgical implications of two distinct groups of patients. Thorac Cardiovasc Surg. 1989; 37(4): 226-230, doi: 10.1055/s-20071020322, indexed in Pubmed: 2799794.

5. Sivakumar K, Singhi A, Mohanraj A, et al. Tumor embolism from a right atrial myxoma leads to acute right heart failure after surgery and atrial septal patch dehiscence. J Am Coll Cardiol. 2014; 63(23): 2579, doi: 10.1016/j.jacc.2014.02.608, indexed in Pubmed: 24768884.

6. Natale E, Minardi G, Casali G, et al. Left ventricular myxoma originating from the interventricular septum and obstructing the left ventricular outflow tract. Eur J Echocardiogr. 2008; 9(1): 84-85, doi: 10.1016/j. euje.2007.01.007, indexed in Pubmed: 17379578.
7. Choi BW, Ryu SJ, Chang BC, et al. Myxoma attached to both atrial and ventricular sides of the mitral valve: report of a case and review of 31 cases of mitral myxoma. Int J Cardiovasc Imaging. 2001; 17(5): 411-416, indexed in Pubmed: 12025955.

8. Javed A, Zalawadiya S, Kovach J, et al. Aortic valve myxoma at the extreme age: a review of literature. BMJ Case Rep. 2014; 2014(pii: bcr2013202689), doi: 10.1136/bcr-2013-202689, indexed in Pubmed: 24642215.

9. Liesting C, Ramjankhan FZ, van Herwerden LA, et al. Systemic embolisation as presentation and recurrence of cardiac myxoma two years after surgery. Neth Heart J. 2010; 18(10): 499-502, indexed in Pubmed: 20978595.

10. Riedl J, Pabinger I, Ay C. Platelets in cancer and thrombosis. Hamostaseologie. 2014; 34(1): 54-62, doi: 10.5482/HAM0-13-10-0054, indexed in Pubmed: 24305775.

11. Lin JN, Lai CH, Lu LF, et al. Fever of unknown origin from a left atrial myxoma: an immunologic basis and cytokine association. South Med J. 2011; 104(5): 360-362, doi: 10.1097/SMJ.0b013e3182142bbd, indexed in Pubmed: 21606720.

12. Malekzadeh S, Roberts WC. Growth rate of left atrial myxoma. Am J Cardiol. 1989; 64(16): 1075-1076, indexed in Pubmed: 2683708. 